\title{
Practice Degree of the Managerial Transparency in the Jordanian Private Universities as Viewed by Their Heads of Departments
}

\author{
Ahmad Badah* \\ Al-Balqa' Applied University, Amman, Jordan \\ *Corresponding Author: badah99@hotmail.com
}

Received April 15, 2012; Revised July 21, 2013; Accepted July 29, 2013

\begin{abstract}
This study aimed to identify extent of the administrative transparency implementation in the Jordanian private universities as viewed by the directors of the academic departments in these universities. To achieve the study aims, a 47-item questionnaire was developed, generally intended to identify the administrative transparency in the private universities. The validity and reliability of the instrument had been duly verified. The study sample consisted of (93) academic departments' directors who were chosen through the random stratified method from the academic departments in the Jordanian private universities during the 2010/2011 academic year. To answer the study questions, the means, standard deviations (SD's), and (ANOVA) analysis of the study sample individuals. The findings of the study indicated that the implementation of the administrative transparency in the Jordanian private universities is carried out to a wide extent. The study findings further showed that there are no statistically significant differences at $(\alpha<0.05)$ significance level in the means of the administrative transparency practicing in the Jordanian private universities that may be ascribed to the (academic rank, years of experience, type of faculty) variables. The study recommended deepening and increasing the awareness of practicing the administrative transparency with the academic cadres at the Jordan higher education institutions. Such awareness could be performed by training these cadres on the transparency practicing concept, and informing them about the experiments of the international universities and the successes they gained as a result of adopting and practicing of such transparency, through developing the values and trends to build an established organizational university culture, in order to stress on the transparency practice with all the university workers. This is essential for the purpose of getting rid of some misused social vals such as favoritism and patronage, which effectively contribute in constraining the transparency practicing, especially when it comes to appoint the administrative and academic cadres, decision making mechanism, and implementation thereof in these universities.
\end{abstract}

Keywords: managerial transparency, universities, heads of departmen

Cite This Article: Ahmad Badah, "Practice Degree of the Managerial Transparency in the Jordanian Private Universities as Viewed by Their Heads of Departments.” American Journal of Educational Research 1, no. 7 (2013): 252-259. doi: 10.12691/education-1-7-6.

\section{Introduction}

With the beginning of the $21^{\text {st }}$ century, the administrative thought witnessed many developments in focusing on the modern concepts in educational management science; one of these concepts is the managerial transparency. As management nowadays is living rapid and consecutive developments and changes in all the educational sectors, and due to the importance of the human element in these institutions, and the huge volume of the challenges faced due to these changes, the need of these institutions for change became even more urgent, which is indispensable to survive and remain operating. For the sake of seeking more efficiency and creation to develop and improve the quality of services delivered by the higher education institutions, in an environment ambient of rapid changes and developments; the practice of managerial transparency is a tempting model for the universities once adequately employed. By proper application of the model higher education, institutions will assure upgrading the service level of the works and students to the best level in a more effective and efficient manner; as well as achieving the optimal use of the material and human resources.

Jordanian private universities, like any other institutions, are continuously seeking modernity and keeping up with the developments and advancements, to promote their outcomes through adapting these concepts, which became an inescapable demand, and a condition provided by most major educational institutions in their dealings and assessment of the performance of the individuals and directorates of different levels. This managerial transparency model is deemed a new method in thought calling for achieving the actual involvement of the workers. This is because all the workers of administrative and academic cadres should bear their full liabilities and 
responsibilities in achieving the goals and implementing the university objectives. Therefore, there would be no secret or ambiguous thing in the university, and the information and figures indicating the achievements and results and facts of the university work should be published, and within their hands and access.

Transparency, as a global term, gained significant importance and wide reputation in the field of the international efforts to combat corruption of the governmental systems, due to the successful experiences in some countries such as Brazil, Turkey and Malaysia, which eradicated corruption from its governmental systems as a result of applying transparency in the practices of these governments [18].

Availability of the administrative transparency is the most important factor in fighting the managerial corruption. It is also one of the strategies that the countries follow to fight the corruption of different shapes. The increase of the transparency level in the administrative transactions means the clarity of the procedures and avoidance of routine and transaction complexity [4].

Efforts and programs for reinforcing the transparency, impartiality, and administrative accountability, as well as combating corruptions, gained wide attention and interest both at the national and international levels, and the development related international organization placed more and more attention to this issue. Ashour [9] indicates that the World Bank for Construction and Building as well as the International Monetary Fund consider that corruption fighting and building impartiality are among their strategic priorities for their work; and even among the conditions for what they provide of aids to the countries, and funds for projects [6].

Interest in the managerial transparency in the higher education institutions increased since the beginning of the $21^{\text {st }}$ century, with the increase in the official interest and direction toward the educational reformation internationally. It was noteworthy that educational administrative systems were lagging to be in line with the developments and advancements in the globalization, and knowledge, information and technological revolution age. Given these facts on the grounds, as Durnev [10] indicated, the calls emerged to set active systems for the educational transparency in the universities to include their inputs, transactions and outputs at all levels, the higher education stakeholders soon put suitable criteria and standards within an integrated transparency system, that will direct and organize their supplies and credibility degree. Therefore, attention shall be particularly paid to the type and quality of the information provided or taken, as many mistakes and problems are entailed in such information [8].

Administrative transparency in the universities includes the free flow of information, and that the systems with transparency possess open communication systems in all the directions. This is due to the fact that the application of the administrative practices purporting transparency may be solutions of the problems the Jordanian private university are experiencing, which may be based on traditional principals; as they, with their different levels and quality of services provided, work toward updating their administrative and get it in line with development processes, through endeavors to apply administrative concepts such as transparency [2].
Some educational institutions found many advantages and positive effects on applying transparency as maintained by Martiny [17]and Marilyn [16]as they work toward combating corruption of all types and shapes. In this concern, transparency of legislations and their precise wording helps in the prevention of deviation. Furthermore, legislation transparency helps in removing obstacles and simplification of procedures and achievements as fast as possible, far away from personal understanding in the interpretation of systems by the workers. Decreasing the bureaucratic routine helps transparency in the laws and regulations to remove all the managerial hurdles, such as unnecessary too many signatures, too many attestations; helps simplify the procedures and broadens decentralization. It further contributes in the simplicity of organizational hierarchy of institutions, easy top-tobottom information access and communication. As a result, the existence of clear and transparent legislations will lead to develop and maintain trust and credibility for all work groups at these institutions [19].

Among other problems experienced by the higher education institutions of the developing countries, is the secrecy of the administrative work style, as many managements view that there are secret issues which should not be disclosed to others. This trend lessens trust and understanding in work relations among the educational parties, as well as denial of the rights of the managerial and academic personnel in assigning their views or identifying their demands and expectations[14].

The researcher reviewed a number of previous studies of the managerial transparency theme as follows:

Al-Shammari [5] conducted a study that aimed to identify the managerial transparency degree at the Saudi Universities. He selected a random stratified sample of the faculty members of the Saudi universities. The results had shown that the observation degree of the managerial transparency, as viewed by the Saudi universities faculty members was medium. Furthermore, there were statistically significant differences at $(\alpha<0.05)$ level between the means of the managerial transparency degree in the Saudi universities in the views of the faculty members, attributed to the university and academic degree variables, which were in favor of King Abdel Aziz University and the associate professor academic degree. In the light of the study results, the researcher suggested recommendations to simplify procedures and interpret and continuously update the regulations, systems and laws.

Study of Al-Tasheh and Al-Hawamdeh [7] which aimed at identifying the commitment degree of the managerial transparency in the Ministry of Education, Kuwait, as viewed by the employees. To achieve the results of that study, a questionnaire was constructed to identify the commitment degree of the managerial transparency. The results had shown that commitment degree of the managerial transparency was medium, and that there were statistically significant differences in the managerial transparency degree attributed to the gender variable in all the domains, and the instrument as a whole, in favor of the males. In addition, there were statically significant differences in the managerial transparency commitment degree attributed to the academic degree variable in the domains of procedures and work mechanisms between the high school certificate and BA 
degree graduates, in favor of the high school certificate graduates.

Study of Al-Amaireh [3] attempted to identify the managerial transparency level of the directors of education directorates in Jordan, and its relation to each of the pressure and psychological security of the workers in their directorates. The study population consisted of all the workers in the directorates of Education in Jordan, of the first and second category employees. The results showed that managerial transparency degree of the directors of education, as viewed by the workers in these directorates, was medium over all the domains. The highest transparency degree was on the material resources management domain, followed by the learning and teaching management domain, the planning management domain, the human resources management domain, and then the last was the relations with the local community management domain.

Stephens's study [21] titled "Data Management Transparency", which was a theoretical study, focused on the transparency concept in data management, which indicates the communication degree of the organization with the information providers and users in data management. The study further indicated the importance of the data management transparency, represented in applying the accountability and inability to conceal any process through the use of technology. All the results came with a high degree.

Irtaimeh [15] conducted a study titled "Transparency". The study aimed at assessing the Ministry of Education workers' performance. It was a field study on the facts and importance of the transparency impediments. The study population consisted of (1022) employees, and data was collected using a questionnaire which was constructed for this purpose, and was distributed over the study sample $(n=600)$. The study results showed the following: Trends of the Ministry of Education workers toward the study domain were good in general; the most transparency obstacle was the dominant leadership style of the Ministry which does not give an opportunity in sharing the decision taking; and that the Ministry does not provide the required support to establish transparency principle.

In a study by Hancock \& Hellawell [12] titled "The Medium Academic Management in Higher Education: Transparency and Clarity", the researches examined the medium academic management from the dean rank, head of a section or their equivalent, in one of the modern universities in the United Kingdom. They interviewed (12) people in that management for the aim of identifying the transparency degree in dealing with their senior officials and subordinates as well. The study showed that the deans and heads of the sections are, in principle, committed to a very wide extent, in supporting transparency and the free flow of information. Yet they admitted that, sometimes, they dealt in secret ways.

Abu Al-Nadi [1] made a study aimed at identifying the conceptions of the heads of the managerial and academic departments in Al-Yarmouk University about transparencyrelated managerial practices in their points of view. The study population consisted of all the academic and administrative heads of the departments of the university ( $n=69$ ) during the academic year 2001/2002. The study instrument consisted of (40) items that included the areas of: decision taking, instructions, communication and administrative development. The study concluded that the conceptions of the heads of the administrative and academic heads of departments of Al-Yarmouk University on certain managerial practices concerning transparency were high.

The study of Gmelch [11] aimed to identify the relationship between five pressing factors, on one hand: role of the faculty members, managerial relations, absence of transparency, desired expectations and the managerial assignment, and certain functionality and personality in terms of their impact on the roles of the heads of the departments, using the pressure factor of the head of the department. The sample consisted of (523) heads of departments in the United States universities. The study found that the higher the transparency, the lower the conflict of roles was; and the higher the satisfaction of the head of the departments on their jobs, the lower the pressure they feel.

To conclude, many foreign and Arabic studies dealt in the transparency theme in terms of its importance and requirements, both in public and private sectors, as well as the official universities. This study is distinguished from others in that it studied the managerial transparency practices in the private universities as viewed by their heads of the administrative departments. The results of these studies were in line with the effect of certain variables, but differed in others. The researcher benefited these studies in setting the objectives of the current study and its questions, procedures, statistical processing as well as supporting its results in terms of being (or not being) in line with these studies.

Undoubtedly, through the previous studies, the researcher noticed that the responsibility is increasing on the universities due to the ethical dimension of their educational system officials as well its workers. This is because the university system is a significant social perspective, and community judges it through judging the workers' behaviors. In this concern, discriminative or poor administrative practices characterized by the ethical nature may distort the university educational system [13].

The poor or absent transparency in the Jordanian universities may entail a daily increasing administrative corruption and organizational decline. The lack of clear procedures and bases in the laws and regulations, and in the mechanisms for assessing the workers' performance, to provide necessary information for many important decisions, especially the academic cadres (such as promotions, training, teaching burden distribution) that clearly impact the workers' development, and their job satisfaction and motivation, mandates studying the transparency issue. Therefore, this study came to identify the administrative transparency degree in the Jordanian private universities.

\section{Study Problem}

Many private universities are experiencing several challenges due to the global changes and the increasing demand for the improvement of performance, and the need for active managements to propel these institutions toward survival, excellence and continuity. They should continuously search in the different managerial departments to achieve the university objectives, with a 
high performance and effectiveness degree. Given that managerial transparency is one of the most important foundations of the managerial system, therefore, attention should be placed on their development and growth through care and interest in their application degree and practice of transparency. Thus, the study problem is identification of the managerial transparency practice degree in the Jordanian private universities as viewed by the heads of the academic departments in these universities.

\section{Study Objectives}

The study aimed at identifying the managerial transparency practice degree in the Jordanian private universities as viewed by the heads of their academic departments, and through answering the following questions:

- What is the managerial transparency practice degree in the Jordanian private universities as viewed by their heads of the academic departments?

- Are there statistically significant differences at $(\alpha \leq 0.05)$ level of the managerial transparency practice degree in the Jordanian private universities as viewed by their heads of the academic departments attributed to (years of experience, faculty type, and academic degree) variables?

\section{Study Significance}

This study derives its importance by dealing with the managerial transparency and its practice in one of the higher education institutions in Jordan, i.e. the private universities. It gains particular significance for addressing one of the topics that appeared in the modern administrative literature. In this concern, transparency is a relatively new issue not dealt with in the studies both in the local and Arab levels to a sufficient extent. The study also dealt in the need for the study of this topic to make use of in our educational institutions, to keep up with the global developments. Interest in managerial transparency in the private university means an interest in the human element, and an interest in the success of his/her performance and work to avoid the errors and difficulties facing the performance, in order to obtain fruitful results to achieve well defined objectives in conformity with well studied plans.

\section{Definitions of the Terms}

For the purposes of this study, the following terms were defined:

\subsection{Practicing Degree}

The academically, scientifically and socially accepted limit to apply an acquired right inside the university, within certain frameworks and within the limits of the law inside the university, which were measured through the responses of the study sample on the instrument (questionnaire) items, specially constructed for that purpose.

\subsection{Administrative/Managerial Transparency}

Is the full clarity of the university legislations, rules and regulations, the clarity of performance, evaluation and their fairness, through information and data spreading and disclosure, easy access to the information and data, simplification and clarity of the procedures and work mechanisms, easy communication in all directions, objectivity in decision taking, and impartiality in implementing them.

\subsection{Private University}

A scientific independent institutions with a certain organizational hierarchy, certain academic systems, norms and traditions. Their main functions are teaching, scientific research and social service. It consists of a number of faculties and departments of specialized nature; provides various educational programs in different majors and specializations, such as the BA degree and the post graduate studies degrees, according to which degrees are awarded to the students. It is founded, owned, run, managed and supervised by a nongovernmental party [20].

\section{Study Determinants}

The results of this study were determined through the following:

The study was confined to the Jordanian private universities: Zarqa Private University, Jarash University, Philadelphia University, Al-Isra'a University, Petra University, Al-Zaytouneh University, Irbid University and Princess Sumaya University for Technology.

This study was confined to the heads of the academic departments in the Jordanian private universities during 2010/2011 academic year.

This study was confined to the employment of the instrument that measures the administrative transparency degree in the Jordanian private universities as viewed by the heads of their academic departments.

\section{Methodology}

\subsection{Study Population}

The original study population consisted of all the heads of the academic departments working in the Jordanian private universities during 2010/2011 academic year $(n=233)$.

\subsection{Study Sample}

Table 1. Distribution of the Study Sample (Heads of the Academic Departments in the Jordanian Private Universities) as per the Study Variables

\begin{tabular}{|c|c|c|c|c|}
\hline No & \multicolumn{2}{|c|}{ Variable } & No. & Total \\
\hline \multirow{2}{*}{1} & \multirow{2}{*}{ Academic Degree } & $\begin{array}{c}\text { Assistant Processor } \\
\text { Associate Professor } \\
\text { Professor }\end{array}$ & $\begin{array}{c}45 \\
28 \\
20\end{array}$ & \multirow{2}{*}{93} \\
\hline \multirow{2}{*}{2} & Years of Experience & $\begin{array}{c}\text { Less than 5 Years } \\
\text { 5 years more }\end{array}$ & $\begin{array}{c}54 \\
39\end{array}$ & \multirow{2}{*}{93} \\
\hline \multirow{2}{*}{3} & \multirow{2}{*}{ Type of the Faculty } & $\begin{array}{c}\text { Humanities } \\
\text { Scientific }\end{array}$ & $\begin{array}{c}58 \\
35\end{array}$ & \multirow{2}{*}{93} \\
\hline
\end{tabular}


Study sample consisted of (93) academic department heads, representing (40\%) of the total study population, who were chosen through the random stratified method, as per the academic degree, years of experience and type of the faculty/college variables. Table 1 illustrates the distribution of the study sample according to its variables.

\subsection{Study Instrument}

To answer the study questions, the researcher developed a questionnaire which was based on the theoretical literature and the administrative transparency related former studies, such as the studies of: Al-Tasheh \& Al-Hawamdeh [7], Al-Shammari [5], Al-Amaireh [3] , and Abu Al-Nadi [1]. The researcher further explored the views of the academic department heads in the Jordanian private universities. The questionnaire in its final shape comprised (47) items.

\subsection{Instrument Validity}

The validity of the instrument was assured by presenting to a number of arbitrators in the educational management, who assigned their comments and suggestions. In the light of their views, the required amendments were carried out, i.e. deletion, addition or amendment, so that the final shape of the instrument was to consist of (47) items.

\subsection{Instrument Reliability}

The reliability was further assured using test-retest, applying it on a sample from outside the study sample $(n=20)$ of the department heads, with two week interval after the first application. Pearson correlation coefficient was calculated, and the overall reliability of the instruments was (0.93) making it applicable and suitable for the purposes of the study.

\subsection{Procedures}

After defining the study sample, constructing the study instrument (questionnaire), and making sure of its validity and reliability, it had been distributed over the sample members ( $n=93$ ) of the heads of the academic departments in the private universities. Only (85) responded questionnaires were accepted as they contained the full required data, i.e. (91\%) of the total sent to the sample. The responses were posted and data entered in the computer, and were statistically processed using the Statistical Package of Social Sciences (SPSS). Thereafter, the results were formulated, analyzed, discussed and compared with the former studies, and relevant recommendations were made as well.

\subsection{Statistical Processing}

To answer the first question, the means (M's) and standard deviations (SD's) of the questionnaire items were calculated and arranged in a descending order. For the second question, the researcher utilized the One-wayANOVA analysis to obtain the differences among the study variables.

The researched adopted the following standard to judge the managerial transparency practice degree in the private universities, as viewed by the heads of the academic departments of these universities, as the following:

1. Means between 4.2 and 5.0 represent very high practice degree.

2. Means between 3.4 to less than 4.2 represent high practice degree.

3. Means between 2.6 to less than 3.4 represent medium practice degree.

4. Means between 1.8 to less than 2.6 represent low practice degree.

5. Means less than 1.8 represent very low practice degree.

\section{Results and Discussion}

\subsection{Results Concerning Responses of Question One}

What is the managerial transparency practice degree in the Jordanian private universities as viewed by their heads of the academic departments?

Table 2. The M's and SD's of the managerial transparency practice degree in the Jordanian private universities were obtained

\begin{tabular}{|c|c|c|c|c|c|}
\hline No. & Item & M & $\mathrm{SD}$ & Rank & $\begin{array}{l}\text { Practice } \\
\text { Degree }\end{array}$ \\
\hline 9 & The university puts guiding signage at visible places to show the announcement it issues. & 4.88 & 0.67 & 1 & Very High \\
\hline 3 & $\begin{array}{l}\text { The university management communicates with all the workers through multiple and open } \\
\text { communication channels. }\end{array}$ & 4.85 & 0.82 & 2 & Very High \\
\hline 42 & $\begin{array}{c}\text { The university is concerned to provide information to the parents through modern and various } \\
\text { communication methods. }\end{array}$ & 4.81 & 0.69 & 3 & Very High \\
\hline 40 & $\begin{array}{l}\text { The university encourages self management and team spirit through the feelings of all participation in the } \\
\text { objectives and interests. }\end{array}$ & 4.78 & 0.74 & 4 & Very High \\
\hline 8 & $\begin{array}{c}\text { The university allocates special boxes for suggestions and complaints at different places in the } \\
\text { university. }\end{array}$ & 4.76 & 0.64 & 5 & Very High \\
\hline 16 & $\begin{array}{l}\text { The university management allows its performance being assessed by quality assurance agency without } \\
\text { intentional concealment of any information. }\end{array}$ & 4.75 & 0.69 & 6 & Very High \\
\hline 44 & The university accurately documents the results of its workers' performance evaluation. & 4.71 & 0.75 & 7 & Very High \\
\hline 34 & Provides true information about the factual situation of the academic work. & 4.68 & 0.67 & 8 & High \\
\hline 2 & Credibility and trust is prevailing between the management and the workers. & 4.53 & 0.86 & 9 & High \\
\hline 32 & The management employs the accountability system both effectively and publicly. & 4.48 & 0.72 & 10 & High \\
\hline 17 & The management combats the administrative corruption of all types. & 4.31 & 0.65 & 11 & High \\
\hline 43 & The university clarifies the policies, procedures and decisions it takes. & 4.21 & 0.61 & 12 & High \\
\hline 4 & The university links between the programs it provides and the labor market needs. & 4.15 & 0.54 & 13 & High \\
\hline 37 & The procedures and work mechanisms issued by the university are characterized by accuracy and clarity. & 4.11 & 0.72 & 14 & High \\
\hline 35 & Commitment to the professional ethics in the university. & 4.04 & 0.58 & 15 & High \\
\hline 6 & $\begin{array}{c}\text { The university management avoids ambiguity and blur in the laws, regulations and legislations upon } \\
\text { implementation. }\end{array}$ & 3.92 & 0.62 & 16 & High \\
\hline
\end{tabular}




\begin{tabular}{|c|c|c|c|c|c|}
\hline 12 & $\begin{array}{c}\text { The university keeps accurate and computerized records and information at the admittance and } \\
\text { registration department. }\end{array}$ & 3.91 & 0.66 & 17 & High \\
\hline 26 & The university provides a guide of information concerning systems and instructions. & 3.74 & 0.62 & 18 & High \\
\hline 14 & Objective definition of the skills and abilities that distinguish the workers who will be assigned the jobs. & 3.72 & 0.75 & 19 & High \\
\hline 29 & The university provides the workers with timely information and decisions. & 3.51 & 0.72 & 21 & High \\
\hline 41 & $\begin{array}{l}\text { The university adopts definite procedures to ensure the possibility of the administrative accountability of } \\
\text { the workers. }\end{array}$ & 3.44 & 0.64 & 22 & High \\
\hline 15 & $\begin{array}{l}\text { Recruits the human resources able and willing to perform work both qualitatively and quantitatively to } \\
\text { achieve the university objects. }\end{array}$ & 3.41 & 0.58 & 23 & High \\
\hline 21 & $\begin{array}{c}\text { The university provides the workers opportunities to participate in setting performance standards upon } \\
\text { which its performance will be measured. }\end{array}$ & 3.40 & 0.72 & 24 & High \\
\hline 24 & Equality among the colleges, and academic and administrative departments in laws and regulations. & 3.36 & 0.54 & 25 & High \\
\hline 28 & The university highly responds to the feedback and employs it for its development. & 3.33 & 0.72 & 26 & Medium \\
\hline 20 & $\begin{array}{c}\text { The university gets all the workers know the positive and negative aspects of the performance evaluation } \\
\text { process. }\end{array}$ & 3.30 & 0.62 & 27 & Medium \\
\hline 19 & The administration works toward developing the trust and credibility with the students. & 3.28 & 0.65 & 28 & Medium \\
\hline 5 & $\begin{array}{l}\text { The university employs preventative and prompt actions to solve all the problems and facilitate the } \\
\text { students' transactions. }\end{array}$ & 3.24 & 0.75 & 30 & Medium \\
\hline 36 & The university carries out studies, makes plans, and adopts prior policies for problem solving. & 3.21 & 0.65 & 31 & Medium \\
\hline 33 & Adoption of the scientific and practical efficiency as a basic standard for promotion. & 3.12 & 0.78 & 32 & Medium \\
\hline 7 & $\begin{array}{c}\text { The university provides protection and safety of workers who contribute in revealing the administrative } \\
\text { and financial corruption. }\end{array}$ & 3.10 & 0.64 & 33 & Medium \\
\hline 23 & $\begin{array}{l}\text { There are definite and clear procedures inside the university to compare actual performance with the } \\
\text { desired or planned performance. }\end{array}$ & 3.09 & 0.62 & 34 & Medium \\
\hline 13 & $\begin{array}{c}\text { The administration applies the worthiness in judging the workers' performance, whether academics, } \\
\text { administrators or technicians, instead of seniority, experience and age. }\end{array}$ & 3.05 & 0.82 & 35 & Medium \\
\hline 46 & The university clearly defines the functional assignments of the workers. & 2.91 & 0.64 & 36 & Medium \\
\hline 10 & The university applies the rules and regulations without favoritism or discrimination. & 2.85 & 0.63 & 37 & Medium \\
\hline 45 & There is a surveillance system in the university to follow up performance. & 2.71 & 0.74 & 38 & Medium \\
\hline 47 & $\begin{array}{l}\text { The university allows all the workers in the services it provides to inquire, clarify and discuss the unclear } \\
\text { matters, and respond to their inquiries. }\end{array}$ & 2.65 & 0.71 & 39 & Medium \\
\hline 38 & The university accurately defines the duties and responsibilities of its workers. & 2.61 & 0.54 & 40 & Medium \\
\hline 39 & The university explains to the subordinates contents of the newly taken decisions. & 2.54 & 0.81 & 41 & Low \\
\hline 25 & Termination of moody method in dealing with the workers of the university. & 2.40 & 0.74 & 44 & Low \\
\hline 31 & The university develops the self-censorship with all its workers. & 2.38 & 0.75 & 45 & Low \\
\hline 22 & University fights phenomenon of favoritism and nepotism in recruitment and appointment. & 2.35 & 0.74 & 46 & Low \\
\hline 10 & The university applies the laws and regulations without favoritism or discrimination. & 2.26 & 0.77 & 47 & Low \\
\hline \multicolumn{2}{|r|}{ Instrument as a Whole } & 3.55 & 0.72 & - & High \\
\hline
\end{tabular}

As for the administrative transparency practice degree in the Jordanian private universities, as viewed by the heads of the academic departments of these universities, Table 2 shows that item (9) providing "The university puts guiding signage at visible places to show the announcement it issues" ranked first with (4.88) mean and (0.67) SD. Next came item (3) providing: "The university management communicates with all the workers through multiple and open communication channels", with (4.85) mean and (0.82) SD. Item (42) ranked third, which provides "The university is concerned to provide information to the parents through modern and various communication methods", with (4.81) mean and (0.69) SD. Next, came item (40) providing "The university encourages the self management and the team spirit through the feelings of all about participation in the objectives and interests", with (4.78) mean and (0.74) $\mathrm{SD}$, followed by item (8) providing "The university allocates special boxes for suggestions and complaints at different places in the university", with (4.76) mean and (0.64) SD.

This result may be attributed to that the administrations of the Jordanian private universities place high interest and care to the communication process such as posters and signage, suggestion boxes, and modern electronic communication methods, being the pivotal element in the motion and dynamics of the workers and students in the university. Views, thoughts, information, policies and decisions are debated and exchanged among the different departments and colleges of the university to achieve interaction, cooperation and harmony between them, through a cooperative work team having loyalty and belonging; making the public interest a priority over the private interests, which will, in turn, pour into the interest of the student, since he/she is the pivot of the educational process in the university, and because his/her satisfaction level is a reflection of the quality level of the university.

On the other hand, item No. (10) ranked lowest, providing "The university applies the laws and regulations without favoritism or discrimination", with (2.26) mean and (0.77) SD. In the last but one rank came item (22) providing "University fights phenomenon of favoritism and nepotism in recruitment and appointment", with (2.35) mean and (0.74) SD. And before this last item came item (31) providing "The university develops the selfcensorship with all its workers", with (2.38) mean and (0.75) SD. These results may be ascribed to that the university attempts to apply the laws and regulations without favoritism or discrimination; attempts to recruit academic and administrative cadres that are capable and eager to perform work both quantitatively a qualitatively to achieve the short-run as well as the long run objectives of the university. But it encounters many erroneous social concepts and undesired features, which contradict the fairness and transparency concept, such as orientation, nepotism, favoritism and sentiments. Therefore, we need transparency principles in order to get rid of these contradictory concepts; and we need a new organizational 
culture that forms a social environment including a pool of principles, values and basic concepts to practice transparency. These should prevail in the university population to perceive the new changes that will be practiced inside and outside the university. They play the role of human conduct director, and an influential role in the decision taking process as well as the problem solving, faced by the rectors, deans, heads of the departments, and workers while implementing this new methodology, which will help in achieving the mission and strategy of the university. The development of self-censorship with the workers came last in rank, which could be attributed to the difficulty of changing the prevailing pools of principles, values and beliefs among the academic and administrative cadres, in favor of censorship and evaluation carried out by the university, and unifying them through a new organizational culture based on transparency practice. Hence, first we have to develop the self-censorship and feeling responsibility, in preparation for being accepted within the framework of transparency practice. The success of the evaluation and self-censorship process in the academic and administrative work is based on assuming the availability of a high degree of self awareness, of all what it is required to do, and what it requires to have as well. These cadres should hold eagerness and determination to amend and develop their performance to the best continuously.

The Table also illustrates that the overall mean of the items is (3.55) out of (5.00) based on the test used in this study. This indicates that the transparency practice degree in the Jordanian private universities, as viewed by the heads of the departments is performed to a high extent. This study is in line with Abu Al-Nadi's [1] and is not in line with that of Al-Shammari [5].

\subsection{Results Concerning the Responses to the Second Question}

Are there statistically significant differences at $(\alpha<0.05)$ level of the managerial transparency practice degree in the Jordanian private universities as viewed by their heads of the academic departments attributed to (years of experience, faculty type, and academic degree) variables?

Table 3. Means of the Administrative Transparency Practice Degree in the Jordanian Private Universities as Viewed by Heads of the Academic Departments, According to the (years of experience, academic degree and type of the college) Variables

\begin{tabular}{|c|c|c|c|}
\hline Variable & Level & M & SD \\
\hline Years of & Less than 5 Years & 3.58 & 0.69 \\
\cline { 2 - 4 } Experience & 5 Years More & 3.52 & 0.71 \\
\hline \multirow{3}{*}{ Academic Degree } & Assistant Professor & 3.57 & 0.74 \\
\cline { 2 - 4 } & Associate Professor & 3.54 & 0.70 \\
\cline { 2 - 4 } & Professor & 3.52 & 0.68 \\
\hline Type of the & Humanities & 3.56 & 0.69 \\
\cline { 2 - 4 } College & Scientific & 3.53 & 0.70 \\
\hline
\end{tabular}

To answer this question, the means of the transparency practice degree in the Jordanian private universities as viewed by heads of the academic departments, according to the (years of experience, academic degree and type of the college) variables, as shown in Table 3.

For the purpose of identifying the variances in the M's of the administrative transparency practice degree in the private universities, as seen by the heads of the academic departments heads according to the (years of experience, academic degree and type of the college) variables, ANOVA method was employed, as shown in Table 4.

Table 4. ANOVA Analysis to Identify the Variances in the Administrative Transparency Practice Degree in the Jordanian Private Universities According to the (Years of Experience, Academic Rank and Type of the College)

\begin{tabular}{|c|c|c|c|c|c|}
\hline $\begin{array}{c}\text { Variance } \\
\text { Source }\end{array}$ & Variance & $\begin{array}{c}\text { Liberty } \\
\text { Degrees }\end{array}$ & $\begin{array}{c}\text { Square } \\
\text { Means }\end{array}$ & $\begin{array}{c}\mathrm{F} \\
\text { Value }\end{array}$ & Significance \\
\hline $\begin{array}{c}\text { Years of } \\
\text { Experience }\end{array}$ & 0.007 & 1 & 0.007 & 0.03 & 0.76 \\
\hline $\begin{array}{c}\text { Academic } \\
\text { Degree }\end{array}$ & 0.006 & 2 & 0.003 & 5.23 & 0.82 \\
\hline $\begin{array}{c}\text { Type of the } \\
\text { College }\end{array}$ & 0.43 & 1 & 0.43 & 1.98 & 0.17 \\
\hline Error & 18.02 & 80 & 0.52 & & \\
\hline Grand Total & 850.21 & 84 & & & \\
\hline
\end{tabular}

Table 4 indicated no statistically significant differences among the means of he administrative transparency practice degree in the Jordanian private universities, as viewed by the heads of the departments, as per the (years of experience, academic degree and type of the college) variables.

This could be ascribed to that the private universities are subject to the same polices, systems, regulations, instructions and rules issued by the Ministry of Higher Education and Scientific Research, as well as quality assurance commission. Further, the heads of the academic departments enjoy close degrees of experience, efficiency and scientific and academic qualifications, who all work within a one administrative set directed by the board of directors, and owners of the university, which affects and is also affected by the workers at almost the same degree. It is also ascribed to that the Jordanian private universities practices became more mature, independent, and more sensitive to their responsibilities due to their nature willing to adopt the administrative transparency principles. They are also willing to combat corruption, if any, so that it will not affect the profit rates of these universities, which is positively reflected on the conducts and transparency practices at almost the same level. This result is not in line with the results of Al-Shammari [5] and Irtaimeh [15] studies.

\section{Recommendations}

In the light of the results of the study, the researcher recommends to work toward deepening and increasing awareness on practicing the academic transparency by the academic cadres in the higher education institutions in Jordan. This will be achieved by training them on the transparency practice concept, and introducing them to the experiences of the universities workers, and the success they achieved for adopting and practicing transparency through development of values and attitudes, to build a well established university organizational culture. This is essential in order to assure practicing the transparency with all the workers of the universities to get rid of certain erroneous social values, such as nepotism and favoritism, which effectively contribute to recess practicing transparency, especially when the universities recruit the administrative and academic cadres, as well as the mechanism of decision making and implementation in 
these universities by creating an effective administrative and academic control.

\section{References}

[1] Abu Al-Nadi, M. F., (2001). Visualizations of the Administrative Departments Heads in Al-Yarmouk University of Certain Administrative Transparency-Related Practices. Irbid: AlYarmouk University.

[2] Abu Baker, F. A. (2007). Modern Management Systems. A Modern Method to Realize Transparency, Cairo: AL-Faris Press.

[3] Al-Amaireh, A. (2008). Administrative Transparency with the Directors of Education in Jordan, and Its Relationship with the Psychological Pressure and Security of the Workers at their Directorates. Unpublished Ph.D. Dissertation. Amman: Amman Arab University for Higher Studies.

[4] Al-Lawzi, S. (2002). Basics of Management- Managerial Theories, Managerial Process, Functions of the Firm. Amman: Dar-ul-Fikr.

[5] Al-Shammari, S. (2009). Degree of Administrative Transparency Observation in the Saudi Universities and the Difficulties They Are Experiencing. Irbid: Al-Yarmouk University.

[6] Al-Tarawneh, R. (2008). Effect of Applying Transparency on the Administrative Accountability Level in the Jordanian Ministries: A Field Study. Karak: Mutah University.

[7] Al-Tasheh, G. \& Al-Hawamdeh, B. (2009). Commitment Degree to the Administrative Transparency in the Ministry of Education, State of Kuwait, Educational Magazine. Kuwait: Kuwait University, 2 (93) 84-103.

[8] Al-Thabti, M. (2005). Universities, Their Rise, Concept and Functions: Analytic Descriptive Study. Educational Magazine. Kuwait: Kuwait University. 69 (5) 33-48.

[9] Ashour, A. S. (2001). Successes and Failures in Corruption Fighting Programs: Lessons Learnt of Global Experiences, Arab Administrative Development Organization. Seminars and Conferences, Conference of New Horizons of Impartiality,
Transparency and Administrative Accountability, A Strategic Perspective: Cairo Press.

[10] Durnev, A. A. (2003). Essays on Corporate Transparency and Governance. DAI-A 64-06. p.2162.

[11] Gmelch, W. G. (1995). Gordon-s the Stressful Journey of the Development Chair: An Academic In Need of a Compass and Clock. The Journal of Administration. 7 (11) 33-34.

[12] Hancock, N. \& Hellawell, D. (2003). Academic Middle Management in Higher Education: A Game of Hide and Seek. Journal of Higher Education Policy and Management. 1 (25) 4-13.

[13] Hawamdeh, B. \& Jaradat, M. (2005). Application Degree of the Administrative Accountability in the Public Schools in Jarash Governorate. Faculty of Education Magazine. Al-Mansoura. AlMansoura University. 58 (2) 77-85.

[14] Hendel, R. (2008). Issuance of New Horizons Conference on Strengthening Administrative Impartiality, Transparency and Accountability, Arab Administrative Development Organization, Seminars and Conferences. Cairo: Shiehab Publishing.

[15] Irtaimeh, M. S. (2005). Evaluation Transparency of the Workers' Performance in the Ministry of Education, A Field Study of the Factuality, Importance and Impediments of Transparency. Irbid: Al-Yarmouk University.

[16] Marilyn, S. (2000). The Tyranny of Transparency. British Educational Research Journal. 26 (3). 310-323.

[17] Martiny, A. (2001). Factors Restraining Developments of National Economics. Arab Archives Institute in Cooperation with Transparency International and Friedrich Eibert Foundation, February 4.

[18] Meyer, P. (2003). The Truth about Transparency, Available Retrieved 10/ 2010

[19] Piotrowski, J. (2009). Governmental Transparency and the National Performance Review. Implementing the Freedom of Information ACT. DAI-A 64/03. p.1071.

[20] Private Universities Temporary Act. (1989). Article (2) on Definition of the Private Universities. Amman: Alwasiva Pulishing.

[21] Stephens, R. (2007). Transparency of Data Management. DM Review. 10 (17) 28-38. 